\title{
School Leadership and Diversity: Perceptions of Educational Administrators in Greece
}

\author{
Dimitris T. Zachos ${ }^{1, *} \&$ Apostolia Matziouri ${ }^{2}$ \\ ${ }^{1}$ Faculty of Education, School of Primary Education, Aristotle University of Thessaloniki, \\ Thessaloniki, Greece \\ ${ }^{2}$ University of Western Macedonia, Nea Peramos Kavala, Greece \\ *Correspondence: Faculty of Education, School of Primary Education, Aristotle University of \\ Thessaloniki, Box 26, Post Code 54124, Thessaloniki, Greece. Tel: 30-231-099-1252
}

Received: March 21, 2015 Accepted: April 22, 2015 Published: April 29, 2015

doi:10.5296/ije.v7i2.7286 URL: http://dx.doi.org/10.5296/ije.v7i2.7286

\begin{abstract}
The study described here constitutes the second part of a larger project, which concerns the way school administrators dealt with issues associated with ethnocultural diversity and social justice in Greek schools. The paper begins with an extended bibliographic review on school leadership and multiculturalism issues. The second part presents the methodology, a case study strategy based on 50 semi-structured interviews, through which the authors attempted to investigate the administrators' perceptions, attitudes, and management strategies concerning the issues of pupils' ethnic variation in a Regional Unity of Northern Greece. The research focused on how administrators prepare themselves, teachers and schools to address the diverse needs of pupils; how they negotiate with pupils' parents and guardians; how school administrators contribute to the integration of "different" pupils and their families in the local communities.
\end{abstract}

Keywords: school leadership, school life, Greece, diversity 


\section{Introduction}

The central point of the rhetoric that accompanies the introduction of the market economy reforms in the educational system concerns the high targets set for all students in order to mark high academic achievements. According to the package of educational reforms proposed by international organizations like World Bank and the Organisation for Economic Co-operation and Development, priority should be given to the bridging of the gap between the school performance of the students coming from the dominant ethnic group and those from the different ones (Zachos, 2014). This is why in numerous official documents of the Greek Ministry of Culture, Education and Religious Affairs (School Curriculum, Ministerial Decisions, and Circulars) the necessity for multicultural education is underlined. The abstract taken from the introduction of the School Curriculum is characteristic: “... as it happens in all European societies, so does the composition of the Greek society change continuously, enriched with people-vehicles of different linguistic and cultural traditions, resulting in the increase of the cultural variation, a situation considered totally healthy from the perspective of the revival of the dominant traditions. This new reality imposes on every citizen the acceptance and respect of the cultural difference of his/her fellow-citizens, so that everybody lives harmoniously in an environment of cultural, national and linguistic polymorphism. This situation demands the development of dexterities of sociability, communication and participation of everybody in modern social developments" (Hellenic Republic 2003: 4). It is also noticeable that, despite the cuts of the public expenses, none of the programs carried out for the integration of "different" groups (people of Roma origin, repatriated Greeks and minority population of Thrace), has been halted so far. Finally, public administrative members of education, on their own responsibility, keep on organising seminars and daily conferences with multicultural content all over the country.

\section{Multiculturalism and School Leadership}

So far, much research concerning the school integration of students from different sociopolitical environments focuses on the educational policy, the school finances, the social organization of the school unit, the relations between school and the families of its pupils as well as the curriculum, the education of teachers and the teaching instructions (Riehl, 2000:57).

Research concerning what administrators, especially schoolmasters, can do in order to create a suitable learning environment, is limited (Riehl, 2000: 57-58). Nevertheless, there is a strong belief that, if the main goal of schooling is to provide their pupils with the best possible education, then schools need effective leaders (Bush, 2007: 391).

Such a leader can affect decisively actions taking place in school, emphasize on the professional capability of the teachers, the learning environment of school, parental and local community involvement and, finally, the ambitious teaching (Sebastian and Allensworth, 2012: 628). More specifically, in case of schools having high number of pupils of different cultural background, it is believed that schoolmasters can influence student achievement of 
disadvantaged groups by creating with the staff an inclusive school mission (Ross \& Berger, 2009).

When there is a high number of foreign students registered in the school unit, the schoolmaster is the person who creates a school culture that is conducive to learning for all students (Lucas, 2000); a learning environment that encourages the equal integration of all pupils, regardless of their ethnic or socio-economic background; mitigate the inequalities (Rodríguez, 2012). To achieve this goal, he/she promotes cultural awareness and respect for individuals as well as for group differences (Blair, 2002: 188), so that the school can cultivate diversion, cultural pluralism and educational equality.

Pupils must not feel wronged because of their being members of a different group (Kupchik \& Ellis, 2008). They should be treated equally into the school. This pursuit may remain on paper, unless the leaders of the education take care teachers develop a pedagogical repertoire that will render them capable of managing everyday issues that originate from the pupils' diversity (Lingard et al., 2003). In other words, the role of administrators is crucial in the professional development of teachers (Tilman, 2005). A process that will aim at the cultivation of a culture that promotes educational research (McLaughlin \& Talbert, 2006); pedagogical competence; a pedagogical perception and practice that will respect the world-wide values and human rights. This purpose can be achieved by the personnel's training inside school, as well as by the facilitation of teachers to attend undergraduate and postgraduate courses, seminars, daily meetings and social events.

Another crucial part of educational leaders' role concerns their efforts to keep at the highest level the expectations of the teachers regarding the achievements and behaviours all of their pupils (Gardiner \& Enomoto, 2006: 561). That is to say, educational leaders shouldn't allow teachers to have lower demands from their "different" pupils. He/she can greatly contribute with his/her personal intervention to the daily meetings and discussions of the personnel, with his/her overall activity and consistent attitude in favour of equality and democracy in school life (relations with pupils, parents \& guardians, local society).

Concluding, the support of teachers on the side of the leaders and the harmonious relationships between administrators and teachers are precondition for the right function of the school (Perry, 1959: 102). At the same time, these preconditions can be determining for the successful academic course of pupils from different cultural background.

As it concerns the relations of the school leaders with their pupils, schoolmasters should be aware of the cultural background of each child and pursue the creation of an environment that will respect and support all students indiscriminatively (Bondy et al., 2007: 344) regardless of their origin.

Furthermore, by his/her words and actions he/she makes a stand against discriminations and shows zero tolerance to racist incidents. At the same time, the school head has to face the particular needs of each student separately. In this frame, the schoolmaster expresses his/her honest interest and respect in the culture the children bring along with them, encourages new ways of teaching and learning and allows students to speak their mother tongue (Riehl, 2000: 64). That doesn't mean, of course, that he/she has to show tolerance or neutrality towards all 
those cultural elements that oppose to the world-wide human values like respect to human life and dignity, the equality of sexes, the non-violence, the religious freedom etc. On the contrary, the school head should place emphasis on specific elements of the culture of ethnic groups (Gay, 2002: 619), which can be put into good use for their better academic course.

Another element of the schoolmaster's role is that he or she is the person that represents the school in the outside world. He/she is the one who builds strong bonds with parents and guardians as well as with local society. Consequently, his/her contribution is crucial in order to elevate them to allies, to eliminate suspicion, reservation and worry between the two sides and illuminate what everybody stands for. It is worth underlining that the initiatives he/she takes to come close to the families of pupils from different cultural background can play an important role to the successful school integration of these children (Theoharis, 2007: 236). To fulfill this goal, a first and crucial step, as we have already mentioned, is to make sure their language and civilization are respected (Schecter \& Cummins, 2003: 60). Only under this condition, the invitation of parents to participate in school activities and events is meaningful. A second necessary step is the use of the appropriate means of communication, as well as the organisation of such events, that make the school the centre of attraction for all the members of the local community.

However, this venture may easily founder. If the invitation is oral and reported by the children or written exclusively in the official language of the host country, it is highly unlikely that it will reach its receivers. Therefore, the schoolmaster should find a more secure way: the invitation must be written in the parents' language. Otherwise, the school head may inform them by phone calls, recorded voice messages, or visits to their houses. As far as the events are concerned, they could be made up of lectures on topics of common interest, parties, artistic happenings and other events which bring people closer. The next step the school head could take is to encourage parents and guardians of the pupils from different cultural background to share their experiences by talking about the way they lived in their country, the activities they were occupied with and the different perceptions on a series of issues concerning school (role of teacher, rules, rewards, penalties etc). All that information, along with their professional identity and skills, could be evaluated and utilized in favour of students.

Having adopted these ideas and practices, school heads can bring the school closer to the local society, in districts and neighborhoods. In addition, these actions can connect school life with organizations, nets and teams that have social and public interest and aim to help people with different cultural background to integrate into their new environment. A set of actions like the one described previously, opens the way to approaches that move further than the ineffective context of the three Fs (food, festival \& folk dancing). Such actions act as a deterrent to phenomena of ghetto-making and labeling of the minority groups.

In the case of Greece, the official policy towards pupils' diversity at school unit level is implemented through a multicultural approach that ought to preserve the principles of human rights like universality, respect of personality, the peaceful resolution of conflicts, the interdependence of human beings and everyone's participation in decision making 
(Cabredaki at al., 2006). Intercultural education constitutes a central goal of Curricula, as it is repeatedly stated in "teacher guides", that is the books which accompany the school textbooks (Zachos \& Michailidou, 2014).

As it was underlined in the previous pages, the role of the schoolmaster in the school integration and academic success of minority students is substantial as he/she is the one who:

- $\quad$ registers the new students and knows their demographic data, needs and particularities; therefore he/she has the obligation to inform the teachers on them and help with their distribution in classes

- records the difficulties encountered by pupils of different cultural background and recruits all the people and means demanded for their evaluation. After that -and if necessary- he/she promotes petitions for the foundation or continuation of function of supportive structures (reception classes, tutorial classes, enhancing teaching) that can assist the integration of this type of students

- coordinates the actions and activities of teachers of both ordinary and supportive classes as well as the cooperation between teachers of morning and afternoon duty. The latter could contribute significantly to help children trace the best possible academic path.

\section{Methodology}

The research presented here is part of a larger project (Zachos, 2014b, Matziouri, 2014), that regards the connection of school leadership and social justice. More specifically the purpose of this study was to explore administrators' perceptions, attitudes and strategies of managing pupils' ethnic variation in a Regional Unity of Northern Greece. The central research questions ran on how administrators prepare themselves, teachers and schools to address the diverse needs of pupils, how they deal with their parents and guardians, as well as how they contribute to the integration foreign / ethnic different pupils and their families in the local communities. At this point, it's worth noting that the management of diversity as a critical focus for education leadership research has received little empirical attention (2006: 278). To serve this purpose, and the conditions, the range and character of the research, we choose Case Study as the research strategy and semi-structured interviews as its' main research technique. Case study (hereinafter referred to as CS) fulfils the three axes of the qualitative method: describing, understanding, and explaining. This type of method can elicit a plethora of data and a rich in-depth picture not only of the perceptions, attitudes and experiences but also of the overt and covert assumptions of the participants in real situations and environments. Theory produced from CS is "likely to have important strengths like novelty, testability, and empirical evidence" (Eisenhardt, 1989: 548). Case Study, as well as all the rest qualitative research strategies gives the opportunity to the researcher to comprehend more deeply and clearly the personal and human experiences (Spencer et al., 2003).

Case Study differs from researches that are based on samples (Stenhouse, 1985: 265), inasmuch it examines cases that can be considered unique, with little or zero interest in 
generalization (Datta, 1990). It also differs from traditional ethnography insomuch it does not depend on the detailed observation and it does not place the burden on the interpretation but on the exploration (Morow \& Brown, 1994: 251).

According to Bogdan \& Biklen $(1982,58)$ a CS "is a detailed examination of one setting, or one single subject, or one single depository of documents, or one particular event". The unit may be a school, one person, or an organisation. In our case the unit is regional unity (ex county).

The interview is an essential technique of qualitative research, and also one of the most important sources of Case Study information (Yin, 1994: 84). The interview is the main road to multiple realities (Stake, 1995: 64), a characteristic that, for a considerable part of researchers in the service of social studies in Greece, identified it in the past with the qualitative research -especially open interview.

Interviews are an intrusion into the life of respondents who "are subjects not objects of research" (Cohen et al, 2001: 245). Most of interviews are led by the researcher (Rubin \& Rubin, 1995: 2), who must create a comfortable and friendly atmosphere that will contribute to the best possible communication between them. The researcher must win the trust of the interlocutors, so that the latter abandon their fears and hesitations and state freely their points of view keeping the research going on. Only under these conditions, both interviewers and interviewees can discuss their conceptions and their different points of view (Barker \& Johnson, 1998).

\subsection{The profile of the participants in the research}

Forty five (45) school directors (9 women, 36 men) out of 65 (13 women, 52 men), as well as the Director of Education (supreme administrative agent of education at regional unity level) and four ( 2 women and 2 men) out of five school counselors of primary education of the specific regional unity participated in our research. Totally 50 individuals (11 women, 39 men) took part in our study.

As far as their time of service is concerned, four people had from 10 to 15 years of service, 1 person from 15 to 20, 21 people from 25 to 30 years and 7 subjects more than 30 years.

This is indicative of the important role that experience plays in the selection of executives of the organisation.

Regarding their educational credentials, beyond their basic degree (from the pedagogical faculty), a school counselor holds a $\mathrm{PhD}, 15$ possessed a Master of Science and 14 a Diploma of two years retraining courses named "Didaskaleio".

Most of the appointments for the interview were fixed after a telephone contact and only a few after personal communication.

Thirty seven (37) interviews were carried out in the administrators' offices and thirteen (13) outside their workplace (homes and cafeterias). The duration of the interviews fluctuated between 30 minutes and 1 hour and 45 minutes. Moreover all but one were recorded. In the only case that the interview was not recorded, we kept analytical notes. 


\subsection{Data Analysis}

After the first reading, the answers were studied thoroughly, analysed and codified and afterwards they were correlated and grouped based on the views of the interviewees. The themes that emerged from research were reduced to five (the most salient of them), around which we organized the writing of the research. In the analysis that follows, every single theme is presented with words according to the data collected (numbers only play a complementary role). Quotes from the interviews allow us to connect with data from other researches, while interpretations reflect our personal views.

The themes that emerged concerned:

- Personal Experiences, Ideology \& Multiculturalism

- Intercultural Education \& “different" pupils (the role of school, teachers etc)

- Teachers' preparation for intercultural classroom

- Handling of everyday school issues concerning ethnic diversity

- School and the communities of "different" students

\subsection{Personal Experiences, Ideology \& Multiculturalism}

Teachers' beliefs affect their attitudes inside the class (Gay, 2009, 144). In the same way administrators' conceptions, ideology and experiences seem to influence the way they pose themselves towards pupils from "different" cultural backgrounds. In the case of Greece, it is likely that all these factors play an even more important role, as school heads receive no special education.

More analytically, when a teacher is chosen to become schoolmaster, he/she is not obliged to get some further training that could possibly help him/her to adopt a more favorable attitude towards "difference". Therefore, every teacher selected for this post, has to consult and study the sources all by him/herself in order to get informed on the laws, decrees and decisions that determine the limits of his/her actions.

It's also noteworthy that the dispersions and contradictions among some of those laws, decrees etc., as well as the bureaucratic burden make the work of a new schoolmaster even harder. In several cases there is even ambiguity in "who is responsible for what". This fact can perfectly lead to misconceptions, misinterpretations and violations of law. This can also prove to be dangerous for "different" pupils, especially nowadays in circumstances of financial crisis. Indicatively, though our intention is not to express the codified answers in numbers, we state that half of the administrative members keep a negative or neutral attitude to culturally differentiated children.

“(...) Well, I see them with suspicion, as all Greeks around me. This is not so unnatural. Every society feels threatened by some people. Those may be Albanians, Roma-Bohemian-Gypsies... however they are called... isn't it? Or they may be Bulgarian, Blacks.... anything different in comparison to what prevails in the society. The society feels it's threatened" N.L. 
"Personally I'm prejudiced. I don't like seeing regions where the majority of inhabitants consists of foreigners. " E.P.

The fact that some administrators have adopted xenophobic attitudes and racist ideas is alarming, for that a school practice based on them can result in discriminations, exclusions and racism. It's worth saying that in Greece there are few administrators who are party members of the Golden Dawn (No Name Author, 2014). Notably, Greek Justice prosecuted the leaders and some members of Golden Down accusing them of cultivating racist hatred and causing racist incidents (including murder). What is the practice of such a director towards pupils from different ethnic background? Is it consistent with his ideology or with the relevant legislation?

"I have come lately to consider myself racist -in quotations always- with all those incidents happening in Greece... Once I slept in the house with the key outside my door and now the majority of them -I don't know, I haven't looked into the statistics regarding these actions-I don't know if they're committed by foreigners or natives but this place is come one come all, nothing but an unfenced vineyard. We're scared now. It's not accidental that the political party of Golden Dawn (nationalists) is the third most popular." A.T.

Another remarkable case is the category of those school heads, who, without possessing the suitable political culture, adopt irrational, extreme-rightist theories about the role the immigrants play in this conspiracy game.

“...That is to say there's a limit in everything. There must be a break... I have the impression that evil plans on Greece emanate from some countries, plans ... I don't know... of ethnological adulteration... from some places where decisions are taken. Not where immigrants come from, but generally. It's a dangerous phenomenon, I would say." N.T.

Noteworthy that some of the administrators that participated in our research seemed to ignore the legislation, especially that part which concerns the school attendance of the pupils from different ethnic background. As a result a few of them seem to show tolerance in vociferous cases of discriminations or racist incidents. Such was the case in Nidri (Lefkada Island), where a kindergarten's teacher was removed from her position by the Administrative Head of the region because -during a project of intercultural education- she asked the pupils to raise both a Greek and an Albanian flag! A few days later and after the outcry, the teacher was justified. However, such episodes are very likely to affect negatively the promotion of intercultural approach in Greek schools, as they discourage and disappoint teachers.

"...on the one side you're asked to apply multiculturalism and on the other to make a reference to Albania to the students of $5^{\text {th }}$ or $6^{\text {th }}$ class for the anniversary of $28^{\text {th }}$ of October [the day that Greece rejected Musolini's ultimatum to surrender its territories to the Italian army and started its military involvement in the second World War II]. It goes without question that this can only cause conflict. It's reasonable. Everybody saw what happened when an Albanian student became flag-bearer. We had lots of big problems and we all know what happens in these cases... the colleagues lower the marks of the Albanian. Everybody knows." 


\subsection{Intercultural Education \& “different” pupils (the role of school, teachers etc)}

Intercultural Education is not limited to "different" children, but is necessary to all, given that the values of solidarity, peace, human rights, cooperation and understanding as well as the fight against discriminations, exclusion and racism concern the whole of the student population.

"Multinational education for me is a philosophy. It doesn't necessarily mean that I have to apply a specific program. It's a philosophy that rules everyday life... As a consequence, we don't focus on specific topics and it's not targeted... We should put forward the cultural wealth that every child carries." O.R.

However, is the school prepared to take up initiatives to help the integration and successful academic course of "different" pupils? All in all, there is currently a legal frame concerning the function of school units that seems to be favourable, as, firstly, it's predicted that:

"...they are registered without the proper documents to the school unit. I think that it is a very positive step that keeps the doors open to a school that offers education to every citizen who lives in this society, in this country." D.X.

Secondly, there is always the possibility to activate compensatory measures:

"...Well, for the foreigners we have the Tutorial Class..... as a school we follow this procedure to found it, as well as to find the material to make it work and it did work ... hm, yes, there were also the Classes of Reception $1 \& 2$ for those who just arrived in Greece or have been living here for several years." B.Z.

Nevertheless, all these initiatives take place in a school that doesn't take into account the cultural background of "different" pupils. This cultural background is ignored by the Curriculum and school units, which, though they're given -by the law- the chance to hire foreign teachers to teach their mother tongue, they don't do it (Zachos, 2014). The school must provide every support to these children for their academic success, because their family is not in a position to do so.

"Well, now, if his parents work in different shifts, it's tough. We see that some children are not looked after...the one goes to work the other goes away and we're left here trying to do our best by Enhancing Teaching... Basically, men firstly seek to satisfy their essential needs and afterwards ....... let alone that even Greeks no longer care for the education of their children. It's first of all a matter of money." K.B.

Another dimension that is worth being noted, is the bureaucratic procedures that accompany the adoption of these supportive structures, a fact that troubles and disturbs the participants in our research.

"I won't waste my precious time talking about all those endless statistic forms we complete for every single one of them... where he comes from etc. etc. and I don't know if the only thing left in the end is the labour of the school ...... and I don't really know if the Ministry takes them into account, 'cause I don't trust their organization!' N.N.

\subsection{School Leadership and teachers' preparation for intercultural classroom}


School leaders can play a decisive role building bridges between teachers and pupils with a different cultural background. In the first stage of this procedure he/she is commissioned to appease teachers' anguishes concerning the difficulties working in such an environment (especially of those arriving for first time) (Boyle-Baise, 2005: 452). In other words, the school leader is the one that has to encourage and guide the inexperienced teachers:

"I tell the new teachers: "You must love children. Much more these children [from different culture], who -well, I won't say they're deprived of love-are deprived, however, of love gestures, because of the low educational level of their parents, the difficulties they face in everyday life......These children certainly lack caress, a good word... We make sure the teacher provides all that." T.N.

In the second stage, school leader is the person bound to give instructions and guidelines:

"I would suggest they be careful, so as not to say or do something that will offend their origin or their parents or their language or their different religion". I.B.

Teachers are members of a given society and -as anyone else- they're inundated with the norms and stereotypes imposed by this society. As a consequence, a considerable number of teachers may have been influenced and apply discrimination practices or even adopt racist behaviours to pupils from different background. Therefore, the school leader must familiarise them with issues around "difference" that have been so far taboos (Milner, 2010: 121).

"I am the first to set the example by approaching each student separately and the rest colleagues, as I have in many cases seen, follow: that may be a tender touch ... get closer a little... ask them a few things about themselves... they're also very responsive to a salutation, as they're children with very rich sentimental world". T.S.

There is also a strong need for the head to cultivate a positive climate, which will not only deter the manifestation of such attitudes and behaviours, but will also favour the integration of these pupils and their academic career. He/she may additionally put him/herself at the head of actions bound to train or enhance the educational background of teachers, so that they adopt a positive stance towards cultural differentiation (Silverman, p.296, p. 321-322).

"To give a boost to these children, you will need specialized knowledge and skills. Unless you have obtained them at University, you must make your own research, ask and learn the reason why these children behave like that. It's expected that they will cause trouble inside the class, unless they find interest." P.M.

With regard to the content of these training courses, it came as a useful conclusion that those in the service of education who participated in our research are not willing to put up with more theory. Instead, they'd like to see the procession of such everyday problematics in practice.

"To my mind all those theoretical seminars do not offer anything essential. I can read all that by myself. I don't need to hear it from someone else. What I don't know and I need to see is the practice inside the class." T.T. 
As it appears in equivalent researches (Sachs \& Logan 1990), this type of training hasn't rendered teachers more critical, capable of deeply comprehending, questioning and modifying their behaviours and strategies. It seems that most of them search for tested and successful "recipes".

“...What I mean, after all, is that I don't see practical approaches. We need people to come and discuss with us, help us in our problems, because well and good with all these seminars and the like -let alone they're in fashion lately because of the E.U., Comenius programmes etc. etc. - but we need to see how to deal with this complicated situation inside the classroom."

\section{Handling of Everyday School Issues Concerning Ethnic Diversity}

In every school, the heads of which participated in our research, there was a considerable percentage of foreign pupils, either high or low (Table I). The children of immigrants, repatriated Greeks from the former Soviet Union and children of Roma origin fall under this category.

Table I. Pupils from different cultural background in the schools of our research unit

\begin{tabular}{cc}
\hline $\begin{array}{c}\text { Number of school units } \\
\text { Percentage of pupils \% coming from different } \\
\text { cultural background }\end{array}$ \\
\hline 20 & Up to 10 \\
15 & From 10 to 20 \\
4 & From 20 to 30 \\
3 & From 30 to 40 \\
2 & From 40 to 50 \\
1 & More than 50 \\
\hline
\end{tabular}

Despite this fact, most school leaders neglected or downgraded the ethnic variation of the schools population, because, according to their estimation, these children have been incorporated and they are no longer distinctable.

“...we don't have any problem, they've adapted, incorporated.” B.P.

"Fortunately we don't have such. Unless they're incorporated, it's logical that I as a head should try to make them feel they're not an alien body." R.T.

"First, nowadays those children have been assimilated. I've been through a lot of difficult situations. In 1990, when they arrived, I was in Z... . You see, basically, most of them came from the ex Soviet Union. ..... Things were really tough then...” A.B.

As it is described and in other researches (see indicatively Aveling, 2007; Ryan 2003), school leaders refuse to recognize racist incidents or incidents of discriminations at the expense of pupils of different cultural origin. However, the problem exists and racist incidents seem to multiply in the context of financial crisis (Spanou, 2013). Those phenomena increased during 
the period we carried out the research, a period marked by the illegal action of members of Golden Dawn party. Most of those actions were not registered, while some others remain unpunished, a fact that contributed to the rise of racism and discrimination in Greece.

"Go! Go find works elsewhere, in another country". That incident might have been the only one but it troubled us a lot. I invited parents, we discussed and they helped me solve this problem. Both parents and students understood." I. G.

The rise of nationalism and the spread of racist ideology affected children deeply. In several cases, the school heads who took part in our research mentioned that they had stood up for a foreign student from attacks of native students.

"To my great displeasure, I've realised that parents have a great impact on their children, channeling their thinking. When a parent has a fixed idea in his/her head, it's more than sure that he/she will pass it to the child. The latter is faced with a dilemma: he/she goes back home and hears this, he/she comes to school and hears another and, as a consequence, he/she gets confused...You see, he/she's still a child, he/she's immature and lets that "nationalist" thing come out, with or without quotations. Let me repeat that our society is not mature, because it carries on its shoulders the heavy load of history.” N.Z.

It has also been recorded that quite often, tension is caused because of the parents' demand that their children not consort with foreign students. In many cases the choice of the flag-bearer constitutes the bone of contention. It seems that many parents refuse the right to foreign students to become bearers of the Greek flag, despite the legal clause (according to which, the student that combines the best marks accompanied by ethos takes it).

In spite of this confusion and the absence of a clear legal frame that encourages initiatives, there are school leaders who do their best to counterbalance the situation:

"I tried in the past to start an afternoon Albanian language class. There was an Albanian teacher working in the fields and the Albanians suggested that he teach their children the Albanian language exclusively at their own expense. That triggered conflict with the local community. Now you may wonder why I was on their side: I was an immigrant in Germany and we had made the same petition." G.L.

\subsection{School and the communities of "different" pupils}

The corner-stone of intercultural approach is the development of bonds among the members of different communities. The adoption of this perspective on behalf of the school entails that teachers get close to the communities of their pupils. The first step is that the parents pass the threshold of the school and participate in the activities its members organize.

“...When I said that the school must open its gates and discuss with the parents, that's what I meant (...). An issue like racism is included in our school event and there will also be a speech and a discussion and a lot of activities related to the topic..." D.C.

Prejudices and reciprocal mistrust haunt the relations between school and parents. Few teachers achieve to establish a constructive way of communication and interaction with 
parents and guardians (Walker \& Dotger, 2011:62). But which are the ways and means that school has at its disposal to succeed in this attempt?

"We must fulfill some requirements, so that these parents will come. For instance, the time and day of these meetings, if there will be interpretation or not (...) if you're going to do something just for the sake of formality, then don't do it at all." O.E.

Is a formal (either oral or written) invitation sufficient to bring foreign parents to school? Is their participation limited to them being informed on their children academic performance or being present in celebrations organized by the school or does it include their involvement in the administration of the school like the Parents' Association?

"In the celebrations... it's beyond every question; I do invite them and I'm glad they attend. Now, as far as the Parents' Association is concerned, I keep my reservations. I wouldn't exclude their participation in it-I never would- but it wouldn't make me feel happy, if foreigners presided. I don't know if it's fair or not but it's true from my perspective." T.K.

"We invite them, but I see reluctance. Maybe they're afraid, ashamed or ... maybe there's a lack of communication, understanding... whatever... they don't take part in the elections to staff the Parents' Association. ” A.A.

"Evidently they feel inferior in comparison to the natives, especially regarding the language and the communication." X.Z.

As a matter of fact this reality is an outcome of the general reluctance to participate in public affairs.

"Not even Greeks want to take part; how can you possibly expect from foreigners to do so? Honestly. I put pressure on them to participate and set up the Association but in vain. They don't want to." J.S.

\section{In Lieu of an Epilogue}

The research presented here could be a census of administrators' perceptions of a Greek prefecture, as the large majority of them participated in it. Nevertheless, it is a Case Study, and, as one of the five traditions of qualitative research (Creswell, 1998), it does not provide the possibility for any generalizations or rules. However, it provides rich data.

In our opinion, the thematic chosen and analyzed here features several important aspects of the relation between the Greek educational system and diversity. Almost twenty years since the initial efforts to cultivate the intercultural approach, there still seem to be issues that require attention and special treatment. Administrators can play a very important role in "different" pupils' integration to Greek school. That's why the way they're trained and supported is crucial. The perception and the meaning school leaders and teachers attribute to concepts like culture, difference, multiculturalism, racism, as well as the way they comprehend the reasons that cause social inequalities, can contribute to the perpetuation of the present status quo. 
Though the preparation of educators on issues concerning multiculturalism may not always be effective, all of them- and mostly those who possess or intend to occupy leading postsshould have the opportunity to learn critically about social diversity. The improvement of the terms of leaders' preparation on such and similar issues is a condition sine qua non for the improvement of the educational system and, to the end, for a better society.

\section{References}

Aveling N. (2007). Anti-racism in Schools, A question of leadership? Discourse, Studies in the Cultural Politics of Education, 28(1), 69-85. http://dx.doi.org/10.1080/01596300601073630

Barker, C.D., \& Johnson, G. (1998). Interview talk as professional practice. Language and Education, 12(4), 229-242.

Blair, M. (2002). Effective School Leadership: The Multi-Ethnic Context. British Journal of Sociology of Education, 23(2), 179-191.

Bogdan, R.C., \& Biklen, S.K. (1982). Qualitative Research for Education: An Introduction to Theory and Methods. Boston: Allyn and Bacon.

Bondy E., Ross D., Gallingane C., \& Hambacher E. (2007). Creating Environments of Success and Resilience: Culturally Responsive Classroom Management and More. Urban Education, 42(4), 326-348. http://dx.doi.org/10.1177/0042085907303406

Boyle-Baise, M. (2005). Preparing Community-Oriented Teacher, Reflections from a Multicultural Service-Learning Project. Journal of Teacher Education, 56, 446- 458. http://dx.doi.org/10.1177/0022487105282113

Bush, T. (2007). Educational Leadership and Management: Theory, Policy, and Practice. South African Journal of Education, 27(3), 391-406.

Cabredaki, A., Karountzou, G., \& Giapapa, E. (2006). The aim of Human Rights Education (in Greek). In P. Georgogiannis, Intercultural Education: Greek as Second of Foreign Language (Vol. III, pp. 45-58). Patra: Center of Intercultural Education.

Cohen, L., Manion, L., \& Morrison, K. (2001). Research Methods in Education. London: Routledge Falmer.

Eisenhardt, J. (1989). Building Theories from Case Study Research. Academy of Management Review, 14(4), 532-550.

Fullan, M. (2002). The Change Leader. Educational Leadership, 59(8), 16-21.

Gardiner M. E., \& Enomoto, E. K. (2006). Urban School Schoolmasters and Their Role as Multicultural Leaders. Urban Education, 41, 560-584.

Gay, G. (2002). Preparing for Culturally Responsive Teaching. Journal of Teacher Education, 53, 106-116. 
Gay, G. (2009). Acting on Beliefs in Teacher Education for Cultural Diversity. Journal of Teacher Education, 61(1-2), 143-152. http://dx.doi.org/10.1177/0022487109347320

Grace, G. (2000). Research and the Challenges of Contemporary School Leadership: The Contribution of Critical Scholarship. British Journal of Educational Studies, 48(3), 231-247.

Hellenic Republic (2003). Ministers Decision 210//2003 / B-303 Intersubjective Unified Framework of [School] Programs (in Greek).

Kupchik, A., \& Ellis, N. (2008). School Discipline and Security Fair for All Students. Youth \& Society, 39(4), 549-574. http://dx.doi.org/10.1177/0044118X07301956

Lingard, B., Hayes, D. Mills, M., \& Christie, P. (2003). Leading Learning. Buckingham: Open University Press.

Lucas, L. (2000). Facilitating the Transitions of Secondary English Language Learners, Priorities for Schoolmasters. NASSP Bulletin, 84(619), 2-13.

Maina Datta, L. (1990). Case Study Evaluations. Washington, DC: U.S. General Accounting Office, Transfer paper 10.1.9.

Matziouri, A., Tsioumis, K., \& Kyridis, A. (2014). The Views of School Administrators and Educational Authorities Concerning the Management of Multiculturalism in a Regional Unity of Northern Greece. Journal of International Education and Leadership, 4(1). http,//www.jielusa.org/wp-content/uploads/2012/01/Management-of-Multiculturalism.pd $\mathrm{f}$

McLaughlin, M. W., \& Talbert, J. E. (2006). Building School-Based Teacher Learning Communities. Professional Strategies to Improve Student Achievement. London: Teachers College Press.

Milner, H. R. (2010). What Does Teacher Education Have to Do With Teaching? Implications for Diversity Studies. Journal of Teacher Education, 61(1-2), 118-131. http://dx.doi.org/10.1177/0022487109347670

Morow, R., \& Brown, D. (1994). Critical Theory and Methodology. London: Sage.

Morrison, M., Lumby, J., \& Sood, K. (2006). Diversity and Diversity Management: Messages from Recent Research. Educational Management Administration \& Leadership 34, 277-295.

No Name Author (2012). Golden Dawn Persecutes Kindergarten Teachers (in Greek). (Tvxs.gr), November $\quad 13 . \quad$ Retrieved from http://tvxs.gr/news/ellada/i-xrysi-aygi-diokei-kai-nipiagogoys

No Name Author (2014). Episodic Elections in a Thessaloniki's School (in Greek). (www.Aygi.gr, November 6). http,//www.avgi.gr/article/4721154/epeisodiaki-i-psifoforia-se-sxoleio-tis-thessalonikis 
Perry, G. R., \& Vredevoe, L. E. (1959). What Practices in School Discipline Develop Better Student-Teacher Relationships. NASSP Bulletin, 43, 100-107.

Riehl, C. (2000). The Schoolmaster's Role in Creating Inclusive Schools for Diverse Students: A Review of Normative, Empirical and Critical Literature on the Practice of Educational Administration. Review of Educational Research, 70(1), 55-81.

Rodríguez, M. A. (2012). But They Just Can’t Do It”, Reconciling Teacher Expectations of Latino Students. Journal of Cases in Educational Leadership, 15(1), 25-31. http://dx.doi.org/10.1177/1555458912442605

Ross, J.A., \& Berger, M. (2009). Equity and leadership, Research Based Strategies for School Leaders. School Leadership \& Management, 29(5), 463-76.

Rubin, J. H., \& Rubin, S. I. (1995). Qualitative Interviewing. The Art of Hearing Data. London: Sage.

Ryan, J. (2003). Leading Diverse Schools. Dordrecht: Kluwer.

Sachs, J., \& Logan L. (1990). Control or Development? A Study of In-Service Education. Journal of Curriculum Studies, 22, 473 - 481.

Schecter, S., \& Cummins, J. (Eds.) (2003). Multilingual Education in Practice: Using Diversity as a Resource. Portsmouth, NH: Heinemann.

Sebastian, J., \& Allensworth E. (2012). The Influence of Schoolmaster Leadership on Classroom Instruction and Student Learning: A Study of Mediated Pathways to Learning. Educational Administration Quarterly, 48(4), 626-663.

Silverman, S. (2010). What Is Diversity? An Inquiry into Preservice Teacher Beliefs. American Educational Research Journal, 47(2), 292-329. http://dx.doi.org/10.3102/0002831210365096

Spanou, K. (eds.) (2013). Racist Incidents in Greece and its Confrontation (in Greek). Athens: Ombudsman.

Spencer, L., Ritchie, J., Lewis, J., \& Dillon, L. (2003). Quality in Qualitative Evaluation: A Framework for Assessing Research Evidence. Retrieved from www.strategy.gov.uk

Stake, R. (1995). The Art of Case Study Research. London: Sage.

Stenhouse, L. (1985). A Note on Case Study and Educational Practice. In R. Burgess, Field Methods in the Study of Education (pp. 263-271). London: The Falmer Press.

Theoharis G. (2007). Social Justice Educational Leaders and Resistance, Toward a Theory of Social Justice Leadership. Educational Administration Quarterly, 43(2), 221-258.

Tillman, L. (2005). Mentoring new teachers: Implications for Leadership Practice in an Urban School. Educational Administration Quarterly, 43(4), 609-629.

Walker, J. M. T., \& Benjamin H. D. (2012). Because Wisdom can't be Told, Using 
Comparison of Simulated Parent-Teacher Conferences to Assess Teacher Candidates' Readiness for Family-School Partnership. Journal of Teacher Education, 63(1), 62-75, http://dx.doi.org/10.1177/0022487111419300

Yin Robert K. (1994). Case study research: Design and Methods. Newbury Park: Sage.

Zachos T. D., \& Michailidou, A. (2014). "Others" in Textbooks, The Case of Greek Sixth Grade's History Textbook. Theory in Action, 7(3), 1-25. http://dx.doi.org/10.3798/tia.1937-0237-14016

Zachos, T. D. (2014). Educational Policy and Roma Groups: Some Critical Remarks on the Case of Greece (in Greek). Comparative and International Educational Review, 22. http,//cire.edu.gr/volumes/tefhos-22/

Zachos, T. D. (2014b). School Administration \& Social Justice. From Theory to Practice. In, K.D. Malafantis, E.P. Galanaki, \& A.I. Pamouktsoglou, (eds.) Proceedings of the IE' International Conference of the Greek Pedagogical Association (pp. 776-784). Athens: Greek Pedagogical Association.

\section{Copyright Disclaimer}

Copyright for this article is retained by the author(s), with first publication rights granted to the journal.

This is an open-access article distributed under the terms and conditions of the Creative Commons Attribution license (http://creativecommons.org/licenses/by/3.0/). 